\title{
DISCURSOS SOBRE A LEITURA NA \\ CONTEMPORANEIDADE: \\ ENTRE O TEXTO-PAPEL E O TEXTO-TELA
}

\section{DISCOURSE ABOUT READING IN CONTEMPORANEITY: BETWEEN PAPER-TEXT AND SCREEN-TEXT}

\section{Fernanda Correa Silveira Galli*}

\begin{abstract}
RESUMO
Ancorada na perspectiva teórica da Análise do Discurso, na interface com a Filosofia e as Ciências Sociais, meu propósito, neste artigo, é pensar a circulação dos discursos sobre a leitura na internet. $\mathrm{O}$ corpus analisado se constitui de alguns excertos de relatos escritos por alunos de três cursos de graduação do Ensino Superior (Ciências Biológicas, Matemática, Pedagogia), os quais colocam em evidência a produção de discursividades sobre a leitura do texto-papel para o texto-tela, bem como a relação do sujeito-aluno-leitor com as "novas" tecnologias digitais no mundo contemporâneo e globalizado.
\end{abstract}

Palavras-chave: discurso; leitura; (hiper)texto.

\section{ABSTRACT}

Anchored in the theoretical perspective of Discourse Analysis at the interface with the Philosophy and Social Sciences, my purpose in this paper is to focus on discourses about reading on the internet. The corpus is composed of excerpts of stories written by students of three undergraduate courses (Biological Sciences, Mathematics, Education), which emphasize the production of discourses about reading the text-paper to text-screen as well as the relation of subject-student-reader with the "new" digital technologies in contemporary globalized world.

Keywords: discourse; reading; (hyper)text.

\section{PRIMEIRAS PALAVRAS...}

No intuito de compreender os discursos sobre a leitura na internet, meu objetivo, com o presente trabalho', é apresentar uma problematização sobre os (deslizamentos dos) gestos de leitura do texto-papel para o texto-tela, a relação

\footnotetext{
* USP, Ribeirão Preto (SP), Brasil. fcsgalli@hotmail.com
} 
do sujeito-aluno-leitor com as "novas" ${ }^{2}$ tecnologias digitais e, como decorrência, suas prováveis influências na vida do sujeito-leitor no mundo contemporâneo e globalizado. Para tanto, meu objeto de estudo se constitui de relatos escritos por alunos de três cursos de graduação do Ensino Superior (Ciências Biológicas, Matemática, Pedagogia), os quais colocam em evidência a produção das discursividades sobre a leitura do texto-papel e do texto-tela.

O tratamento interpretativo dado ao corpus de pesquisa fundamenta-se nos pressupostos teóricos da Análise do Discurso de linha francesa, que me permitem trabalhar com os conceitos: a) de discurso - como processo em que o linguístico, o social e o histórico se relacionam, de modo que toda a materialidade discursiva é analisada a partir das suas condições de produção; e b) de sujeito - caracterizado como descentrado, clivado, afetado pelo inconsciente, efeito de linguagem (PÊCHEUX, 1975 [1997]). Frente a isso, adoto a concepção de interpretação, no campo discursivo, como constituição da memória discursiva, que compreende outros dizeres historicamente construídos e que se (re)atualiza em discursos outros.

$\mathrm{Na}$ próxima seção, trago uma abordagem sobre as noções de virtual e de globalização, que fazem parte das condições de produção e contribuem, sobremaneira, na reflexão acerca das discursividades analisadas. Na segunda seção, a dos resultados de análise dos dados, apresento, também, uma breve descrição do corpus que constitui a pesquisa.

\section{DAS CONDIÇÕES DE PRODUÇÃO: ENTRE O GLOBAL E O VIRTUAL}

A globalização tem sido assunto de muitos estudos e discussões, envolvendo fatores diversos e múltiplas tendências. Entretanto, as considerações aqui esboçadas dizem respeito à tendência da globalização no cenário do século XXI, considerando as transformações sócio(ciber)culturais. Por um viés foucaultiano, tomo a noção de globalização como um acontecimento - histórico-social, já que mobiliza sujeito e modos de $\operatorname{ser}^{3}$ - que se desencadeou, a partir da segunda metade do século XX,

1. Esse artigo é um recorte de minha pesquisa de doutorado (cf. GALLI, F.C.S., 2008), (Ciber)espaço e leitura: o mesmo e o diferente no discurso sobre as "novas" práticas conteporâneas. Campinas. 204p. Tese (Doutorado em Linguística Aplicada, Unicamp, IEL).

2. Esclareço que as aspas grafam os vocábulos "novas" ou "novos" no intuito de problematizar a adjetivação.

3. Também nessa linha de raciocínio, Derrida (2001 [2004, p.36]) coloca que "não há acontecimento sem experiência (e isso é o que no fundo, "experiência" quer dizer), sem experiência, consciente ou inconsciente, humana ou não, do que acontece ao vivente". 
assumindo um papel relevante no desenvolvimento dos meios de comunicação e das "novas" tecnologias de informação e assinalando seus processos de difusão. Desse modo, a globalização não se reduz apenas ao comunicacional, mas engloba várias áreas do conhecimento e envolve outras naturezas como política, econômica, tecnológica e cultural, na medida em que:

\begin{abstract}
A "globalização" está na ordem do dia; uma palavra da moda que se transforma rapidamente em um lema, uma encantação mágica, uma senha capaz de abrir as portas de todos os mistérios presentes e futuros. Para alguns, "globalização" é o que devemos fazer se quisermos ser felizes; para outros, é a causa da nossa infelicidade. Para todos, porém, "globalização" é o destino irremediável do mundo, um processo irreversível, é também um processo que nos afeta a todos na mesma medida e da mesma maneira (BAUMAN, 1999, p.7).
\end{abstract}

Nessa perspectiva, a globalização parece que, ao mesmo tempo em que divide, também une; ou pode dividir enquanto pretende unir, de modo que os motivos da segmentação tendem a se assemelhar aos que geram certa uniformidade. Trata-se de um acontecimento que envolve, ainda, a segregação espaço-temporal e a exclusão dos que não podem (ou não conseguem) se inscrever na ordem global, embora o sujeito seja, desde os primeiros dias de sua existência, programado de acordo com padrões sociais preestabelecidos. Junto ao movimento e à transitoriedade, também há o desejo de fixação, e o que é globalização para uns, pode igualmente significar localização para outros, e o que para alguns é sinal de liberdade, para outros significa destino indesejado e cruel, pois os efeitos desta (nova) condição são variáveis e heterogêneos, como a constituição do próprio sujeito. Nesse sentido, parece que

\footnotetext{
alguns de nós tornam-se plena e verdadeiramente "globais"; alguns se fixam na sua "localidade" - transe que não é nem agradável nem suportável num mundo em que os "globais" dão o tom e fazem as regras do jogo da vida. Ser local num mundo globalizado é sinal de privação e degradação social. (BAUMAN, 1999, p.8)
}

Fragmentado, volátil, o sujeito contemporâneo se circunscreve num contexto também em dispersão, que parece colocá-lo numa condição nem global nem local, mas no entremeio de ambas (glocal). Sob a ótica do imbricamento, as considerações de Trivinho (2004, p.5), a respeito do termo glocal, são bastante pertinentes para essa abordagem: glocal é um neologismo resultante da hibridação dos termos global e local, de modo que, sem sutura visível, eles "são um e mesmo e, simultaneamente, nenhum; globalização (ou globalismo) e localização (ou localismo) restam dissolvidos". Nesse sentido, o contexto glocal tende a se configurar como lugar da existência humana, tecnologicamente mediado e "em estrita compatibilidade com as necessidades de reprodução social-histórica", acrescenta Trivinho. No 
material investigado, a ênfase nas práticas que sugerem uma efetiva participação no atual cenário (adquirir conhecimentos, ter informações, fazer pesquisas, etc.) é produzida discursivamente pelo aluno-leitor, a partir do âmbito glocal, de forma a dar legitimidade ao seu discurso.

Com a possibilidade de acesso a informações diversificadas - o que, diga-se de passagem, também se conseguia realizar em outras épocas e de outras maneiras -, o contexto das tecnologias de informação e comunicação tende a construir um ideal de maior autonomia de pensamento e de ação. Entretanto, esses supostos modelos de autonomia enfatizam "um individualismo possessivo ao mesmo tempo em que, contraditoriamente, salientam as obrigações públicas de todos os cidadãos" (AMARANTE, 2005, p.2) ${ }^{4}$, sacralizando um desejo do sujeito, desejo esse que está em conformidade com discursos já instituídos social e educacionalmente, como traz o documento referente às diretrizes do Programa Nacional de Informática na Educação (PROINFO): "Os avanços tecnológicos trazem consigo mudanças nos sistemas de conhecimento, novas formas de trabalho e influem na economia, na política e na organização das sociedades. São responsáveis pelas principais características do modus operandi da 'aldeia global'" (p.2).

A internet, como um espaço de comunicação surrealista, apresenta uma realidade em que "nada é excluído, nem o bem, nem o mal, nem suas múltiplas definições, nem a discussão que tende a separá-los sem jamais conseguir" (LÉVY, 2004, p.12). A cada época, há uma história da humanidade que corresponde a determinada cultura técnica, e a "cultura contemporânea, associada às tecnologias digitais (ciberespaço, simulação, tempo real, processos de virtualização, etc.)", tem criado uma "nova" relação entre técnica e vida social, a chamada cibercultura (LEMOS, 2004, p.15).

A cibercultura tornou-se popular na década de 70, estabeleceu-se nos anos 80, com a informática de massa, e, a partir dos anos 90, com as redes telemáticas, em especial com a internet, cuja emergência contribuiu para desencadear discussões sobre o virtual (LEMOS, 2004). A concepção de virtual não é tão nova como muitos pensam e divulgam, complementa Lemos, já que vem sendo tratada há algum tempo em áreas como a matemática, a filosofia, a comunicação, dentre outras. Assim, o que me interessa nessas reflexões é abordar o virtual a partir das discursividades produzidas no contexto atual, que envolve o ciberespaço. A produção de discursos

4. Amarante enfatiza, ainda, que a globalização - enquanto acontecimento discursivo - tem suas bases ancoradas num modelo "neoliberal" que se revela contraditório, "pois busca conciliar as preferências concebidas individualmente com a seleção de alternativas de política pública que remetem à escolha pública social racional $(2005$, p.2) . 
no cenário do virtual gera mudanças na produção das subjetividades e dos sentidos, na medida em que a concepção de mundo é construída a partir de outros (ou "novos") paradigmas, alterando, pois, a forma de ser e estar do sujeito.

A disseminação da cultura cibernética permeia, então, identificações que ficam entre os valores e as normas sociais e as vontades individuais, de maneira que recursos técnicos - como a internet - acabam por instaurar e moldar o sujeito de acordo com os interesses impostos socialmente, a partir de mecanismos de controle que são instituídos para garantir uma "nova" ordem social. No plano cultural, sempre existiu uma posição cosmopolita, que aponta para duas situações contrárias: por um lado, não há como dissociar a cultura da dependência econômica e política, o que pode restringir o fenômeno cultural a um discurso ideológico; por outro lado, as muitas manifestações culturais prestam-se à materialização de desejos de emancipação e liberdade de pensamento que não pertencem a nenhum modelo de dominação, seja nacionalista ou cosmopolita (SOARES, 1997).

O termo "colonização" soa, então, quase que mais adequado que cosmopolitismo ou globalização, na medida em que, desde o colonialismo europeu da Idade Moderna até a era cibernética global, a dominação tem se intensificado ${ }^{5}$. O desenvolvimento tecnológico tem favorecido um grau crescente de eficiência do modelo econômico atual e, por isso, "um novo imperialismo, mais disfarçado pelo consumismo, mais diluído pelo aparato tecnológico, está-se instaurando num sistema sociocibernético universal" (SOARES, 1997), e a "nova" dialética se situa entre o desejo e a satisfação. Trata-se, então, de um "novo" dispositivo que valoriza o consumo ${ }^{6}$ das coisas, num movimento que envolve a vontade de ter e, juntamente, o vazio de ser, "num tempo de valorização dos desejos, de liberação dos prazeres e de produção do corpo" (SILVA, 2005, p.xii).

Numa época em que, por toda a parte, o estabelecimento de uma fronteira colonial tem sido recusado, a internet tem ocupado o posto de um dos maiores instrumentos da globalização cultural na sociedade tecnológica. Embora sua abrangência e extensão envolvam grandes transformações contemporâneas, no que diz respeito a uma revolução espaço-temporal, há que se atentar para o fato de que, "sejam quais forem as implicações dessa fronteira ciberespacial retórica com relação a nosso passado, ela sugere, talvez de maneira mais insidiosa, um imperialismo

5. Wertheim (2001, p.216), partindo de observações do comentador Ziaudin Sardar, coloca que grande parte da retórica utilizada pelos defensores do ciberespaço vem da linguagem da colonização: "o ciberespaço é rotineiramente referido como um novo continente ou uma nova fronteira e sua conquista e colonização muitas vezes comparadas à conquista e colonização do Novo Mundo".

6. Uma abordagem mais aprofundada sobre o "consumismo" faz parte do capítulo 1 da tese. 
cultural em ação agora" (WERTHEIM, 2001, p.217) ${ }^{7}$. Por definição, a fronteira traz a ideia de um lugar em que as coisas estão sendo formadas novamente, a partir do (suposto) "novo". Essa "novidade" encanta os ciberentusiastas e os coloca em situação de "domesticados", ainda que a virtualidade proporcione uma coexistência (velho/novo; passado/presente). Assim se pronuncia Deleuze (1968 [2006, p.182]), a respeito da coexistência:

dois aspectos do tempo, imagem atual do presente que passa e a imagem virtual do passado que se conserva, se distinguem na atualização, tendo, ao mesmo tempo, um limite inassinalável, mas se permutam na cristalização, até se tornarem indiscerníveis.

Se a internet enquanto produto das tecnologias de informação e comunicação parece envolver o virtual como novo, que não é totalmente novo, torna-se relevante uma exposição sobre o conceito. Pensar numa genealogia do virtual significa uma tentativa de trilhar os caminhos pelos quais o virtual tem passado até os dias atuais. Isso não quer dizer que a pretensão seja a de mapear tal percurso no que diz respeito às várias possibilidades potencializadas pelo virtual; ao contrário, interessa-me tratar do virtual para compreender a atmosfera da cultura contemporânea e refletir sobre a internet - enquanto parte das novas tecnologias de informação e comunicação -, em especial no que se refere às discursividades sobre práticas como a da leitura na tela. Junto a isso, estão outras questões como o sujeito e os objetos, o real e o imaginário, o deslumbramento e o aniquilamento, dentre muitos outros conceitos que se opõem e, ao mesmo tempo, se complementam - e que envolvem, de certa forma, a virtualidade.

Numa trajetória sob os pontos de vista filosófico, antropológico e sóciopolítico, Pierre Lévy define o virtual como "um complexo problemático que acompanha uma situação, um acontecimento, um objeto ou uma entidade qualquer, e que chama um processo de resolução: a atualização" (LÉVY, 1996, p.16). Embora o autor fale em atualização, propõe o virtual como "não-presença" ${ }^{\text {, }}$ opondo o real ao virtual: quando um sujeito, um objeto, ou uma informação se virtualizam, tornamse "não-presentes" e acontece a desterritorialização. Essa definição do virtual como positividade, uma das mais conhecidas e utilizadas em pesquisas sobre as novas

7. Há, ainda, a materialização e supervalorização do inglês como idioma universal, na medida em que algumas expressões como bome pages, sites, net, e-mail, dentre muitas outras, vão além do contexto cibernético e parecem representar a instituição de um fator "concreto" da globalização, a ponto de já se encontrarem, inclusive, dicionarizadas (cf. HOUAISS, 2001).

8. A ideia de "não-presença" é ilustrada, também, por Michel Serres, em seu livro Atlas, numa discussão polêmica sobre a filosofia heideggeriana do "ser-aí" - ou existência, do alemão Dasein (LÉVY, 1996, p.20). 
tecnologias, em especial no campo da Educação, não contempla os propósitos da presente discussão, que caminha no sentido de problematizar as dicotomias e apontar os imbricamentos (de acontecimentos, de práticas, de identidades, etc.).

Numa outra perspectiva, que me parece mais pertinente para as reflexões aqui propostas, se insere a visão de Deleuze sobre o virtual: a partir do ponto de vista da percepção e das noções de repetição e deslocamento, o filósofo defende que o antigo e o atual são coexistentes em relação ao objeto virtual, que se desloca sem atribuir originalidade ou derivação às duas séries (antigo e atual), pois elas colocam "em jogo termos e sujeitos diversos, numa intersubjetividade complexa, cada sujeito devendo seu papel e sua função em sua série à posição intemporal que ocupa em relação ao objeto virtual", que também não é tratado como original (1968 [2006, p.156]). Deleuze afirma que todo objeto é duplo e que o virtual define-se como uma parte do objeto real, como se tivesse uma de suas partes no virtual e nele se incorporasse.

Assim, a concepção deleuziana de virtual é diferente da definição dada por Lévy, na medida em que, para Deleuze, não há oposição entre virtual e real: "O virtual não se opõe ao real, mas apenas ao atual. $\mathrm{O}$ virtual possui uma plena realidade como virtual" (DELEUZE, 1968 [2006, p.294]). É preciso, contudo, alerta o autor, não confundir o virtual com o possível, pois "o possível opõe-se ao real; o processo do possível é, pois, uma 'realização'. O virtual, ao contrário, não se opõe ao real possui plena realidade. Seu processo é a atualização" (p.298). A realização se dá a partir do possível e o real é semelhante ao possível; ao contrário, a atualização do virtual se dá, pois, na/pela diferença: (re)atualização de já-ditos que, enquanto memória, são (re)construídos numa outra instância discursiva. Desse modo, para o que me interessa abordar, o virtual é, enquanto lugar de subjetivação, um conceito que diz respeito à produção de discursividades outras, que envolvem a repetição "tanto no que se atualiza quanto na atualização" (DELEUZE, 1968 [2006, p.310]).

Com a propagação cada vez maior do uso da internet, o espaço virtual proporciona relações virtuais que se configuram como práticas sociais reinstituídas no cotidiano. Com o virtual, o sujeito também virtualiza seus hábitos: a compra, a venda, o uso de serviços públicos, a busca por novas amizades, a pertença às novas comunidades, a troca de informações, o envio e recebimento de correspondências, o ensino, a aprendizagem, a pesquisa, o conhecimento, enfim, "tudo" por meio da internet, como aparece nos recortes analisados na próxima seção. 


\section{DOS DISCURSOS: ENTRE O TEXTO-PAPEL E O TEXTO-TELA}

Os discursos que constituem o corpus da pesquisa aqui abordada são compostos por relatos de alunos de três cursos de nível superior (Ciências Biológicas, Matemática, Pedagogia) de uma instituição de ensino particular, do interior do Estado de São Paulo. A escolha se justifica pelo fato de ser o local onde atuava como professora na época da coleta do material, que foi realizada em dois momentos: a) questionário escrito ${ }^{9}$ por alguns alunos do último ano dos cursos de Ciências Biológicas e Pedagogia; e b) relatos escritos ${ }^{10}$ pelos alunos do segundo ano dos três cursos. Interessa-me, assim, observar o discurso desses alunos sobre sua prática de leitura na internet: as diferenças com relação à leitura do texto-papel, suas preferências de leitura, para que e por que usam a internet, etc., - dizeres que se mostram afetados e constituídos por outros discursos (pedagógico, religioso, científico, etc.), bem como pela vontade constitutiva de fazer parte da sociedade da informação, como é próprio do sujeito do mundo contemporâneo.

Retomando o pressuposto de que os discursos são produzidos a partir da inserção do sujeito-aluno num cenário global das "novas" tecnologias de informação e comunicação, o que faz com que ele se constitua no atravessamento dos suportes tradicionais (impressos - livros, jornais, revistas) e tecnológicos (virtuais - TV, internet, celular), busco identificar, na materialidade linguística do material analisado, a leitura como um processo que carrega traços de outros imaginários construídos socialmente, de maneira que as noções de texto-papel e texto-tela acabam por se confundir. Dos recortes ${ }^{11}$ abordados abaixo, ecoam vozes das quais os alunos-leitores se apropriam para se posicionarem sobre a necessidade - criada e já estabelecida - da leitura na internet:

A6_PED(1) - ... Hoje em dia uso a internet para ver as notícias que não consigo ver no jornal tradicional, procuro informações sobre a área em que atuo e me atualizo em vários aspectos, como sociais, culturais, etc. ...

A9_MAT - ... Acho a leitura pela internet muito bom, pois se não tenho tempo de ir à banca comprar jornal ou, não assino o mesmo, acesso a Internet e fico por

9. Composto por perguntas abertas sobre a relação sujeito-leitor e hipertexto. Projeto-piloto da pesquisa.

10. A partir de um texto introdutório sobre o que poderiam escrever acerca da leitura na internet.

11. Sobre os excertos utilizados, destaco que: i) são representados pela letra A (aluno), seguida por um número de sequência e sigla do curso (BIO - Ciências Biológicas, MAT - Matemática, PED - Pedagogia); e ii) mantêm-se da forma como os alunos escreveram, embora apresentem "problemas" de escrita, do ponto de vista da norma culta padrão da língua portuguesa. 
dentro de tudo o que rola no mundo. Porém, pude notar que, muitas das notícias que são colocadas na rede, têm erros gravíssimos de escrita (talvez, lendo na tela do computador não percebemos, mas se imprimimos, vemos claramente). ...

A rede de relações discursivas que se instala, nesses recortes, estabelece para a leitura na internet uma (quase) mesma função atribuída ao jornal (impresso ou televisivo): a de informar e atualizar. O tempo-acelerado e o espaço-reduzido, características da contemporaneidade, funcionam como parte de uma demanda que coloca em jogo a circulação das informações (notícias), de modo que as práticas discursivas assumidas pelos alunos se sobrepõem mutuamente, num processo que envolve tanto a (des)territorialização da informação quanto do próprio sujeitoleitor. Nos dois suportes (jornal on-line e jornal impresso), a busca dos alunos parece ser pelo que é mais simplificado (conteúdo), ou pelo que incita uma prática mais superficial, uma leitura mais habitual (jornal). Sobre esse aspecto, afirma Bruno (2006, p.157), o interesse do meio digital não está "na verdade e na profundidade, mas na performance, nos fluxos de informação e comunicação", nos cenários que orientam as ações e as escolhas do sujeito-leitor-consumidor.

Nessa perspectiva, o ciberespaço produz, no imaginário do sujeito-leitor, uma aparente liberdade que, efetivamente, apenas corresponde a uma construção com vistas a nortear as buscas e a proporcionar identificações (... me atualizo em vários aspectos, em A6_PED(1); ... fico por dentro de tudo, em A9_MAT). O que antes era função do jornal-impresso, agora tem como concorrente a internet. Quais as diferenças entre um suporte e outro? $\mathrm{O}$ que leva os alunos-leitores a optarem pela notícia on-line em detrimento da impressa? $\mathrm{O}$ deslocamento de práticas é marcado por uma temporalidade que se mostra mais breve - materializada no emprego das conjunções coordenativas que expressam finalidade (...procuro informações sobre a área em que atuo e me atualizo, em A6_PED(1); ... acesso a Internet e fico por dentro de tudo o que rola no mundo, em A9_MAT) -, e, também, por um espaço mais atrativo.

Essa atração pode ser traduzida em facilidade, na medida em que a internet se configura como "um espaço aparentemente sem bordas ou limites, cria a ilusão de um sujeito-navegador potente, onipresente, capaz de estar e chegar a todo e qualquer porto sem obstáculos ou barreiras" (ROMÃO, BENEDETTI, 2008, p.3). Embutido na facilidade está o modo camuflado de como as informações - no textopapel ou texto-tela - são construídas e disponibilizadas ao leitor, que acaba por ter acesso àquilo que, na sua visão enquanto leitor-consumidor, é apresentado da forma como ele espera. Essa visão ilusória é sustentada pelos desejos que passa(ra)m a contaminar a vida cotidiana e que carregam uma curiosidade em relação ao que se mostra como "novo" - um "novo" que não apaga o "velho", o que aparece, 
naturalizadamente, no uso do verbo (ver), em A6_PED(1), para os dois suportes. Ainda a respeito da "inovação", inscreve outro sujeito-leitor:

A7_MAT - Leitura para mim tem que ser uma leitura dinâmica ou seja jornal, revista e principalmente internet. Não gosto muito de ler livros e sim algo que interesse, principalmente do lado profissional. Leio muito na internet, estou sempre procurando textos sobre grandes empresas, boas oportunidades e principalmente algo que venha me ajuda profissionalmente (testes, dicas, etc...)...

A partir do "novo" suporte que é a internet, a prática da leitura é qualificada como dinâmica, adjetivo que é atribuído, também, por meio da conjunção coordenada explicativa (ou seja), a outros suportes (jornal, revista). O que há de comum na leitura via tais suportes? A opção pelo método de "leitura dinâmica" pressupõe um leitor que busca rapidez, conteúdos mais sintéticos, o que na internet parece envolver, ainda, maior velocidade no acesso (navegação pop-up) e mais variedade (dinamismo da tela, da rede). A dinamicidade é efeito do contexto contemporâneo que, por sua vez, tende a se disseminar na circulação de informações, atribuindo às discursividades um modo de ser ou de estar alicerçado na efemeridade, num processo instantâneo que promove estímulo no aluno-leitor. Nesse sentido, os textos buscados para leitura (sobre grandes empresas, boas oportunidades e principalmente algo que venba me ajuda profissionalmente) indicam o modo transitório que caracteriza o mercado de trabalho atual e o sujeito hedonista.

Motivador, então, parece-me ser o suporte que, por meio da dinamicidade e da transitoriedade, desperta no imaginário do aluno-leitor a possibilidade de adquirir um status profissional - via leitura instrumental para fins determinados de maneira direta e passiva. O transitório, como um tempo-movimento que passa e que marca, instala, ainda, "uma representação coletiva em que se defrontam o tempo vivido dos homens e o tempo produzido pela máquina" (GREGOLIN, 2003, p.107), conflito que se harmoniza na medida em que, de outras maneiras, os discursos se (re)produzem e se constituem no tempo. A novidade instaurada, desse modo, é regida pelo tempo que flui - acelerado e comprimido - e faz com que a tecnologia desperte no sujeito outras fantasias com relação aos textos e aos gestos de leitura, conforme traz outro excerto abaixo:

A4_PED(1) - Sob meu ponto de vista, a leitura na internet ocorre de duas formas: - primeiro: quando preciso procurar artigos, entro em sites de busca e me detenho aos endereços indicados. Nestas páginas, procuro ler assuntos nos sites variados, é uma forma de pesquisar fazendo paralelos. Geralmente seleciono os itens que me interessam e imprimo. A segunda forma é quando resolvo passear, digo quando 
procuro algo, não por obrigação, por passatempo. A realidade é que, no final, acabo vendo muito e nada ao mesmo tempo, pois de uma página pulo para outra e assim sucessivamente. ...

Nesse recorte, a internet é um suporte que proporciona formas de leituras, as quais, marcadas pelas locuções adverbiais indicadoras de tempo (quando preciso procurar... quando resolvo passear...), classificam os interesses do sujeito-leitor. A emergência de uma "metodologia" de leitura aponta para o deslocamento do processo de didatização da leitura do texto-papel para o texto-tela. Dito de outro modo, o recorte traz resquícios de certos procedimentos tradicionais de leitura, por meio da enumeração (duas formas) de caminhos que se mostram delimitados: ou de interesse profissional (material de pesquisa, artigos relacionados à área da Educação), ou de interesse pessoal (lazer, passatempo, passeio, prazer). De meu ponto de vista, tais colocações apontam para o fato de que o método não garante, em especial no hipertexto, o compromisso e o objetivo do leitor no processo da leitura, como permite entrever a conclusão do próprio aluno (...no final, acabo vendo muito e nada ao mesmo tempo...).

Numa mistura de procedimentos distintos e possíveis, tanto no texto-papel quanto no texto-tela-ler, procurar, selecionar, pesquisar, passear, pular-, o mesmo e o diferente parecem se mesclar, transformando a ação de percorrer com a vista (ler), a vontade de encontrar algo (procurar, pesquisar), de escolher (selecionar), com a ação de entreter-se (passear - uma leitura aleatória, sem compromisso, sem objetivos). Como pensar a inscrição da identidade do aluno-leitor se em ambos os espaços - tela e papel - ele parece ser movido pela atratividade da máquina? De maneira fragmentada, as identificações do sujeito-leitor são (re)construídas nas práticas discursivas, nas diferentes posições subjetivas que se (con)fundem: ora como leitor do texto-papel, ora do texto-tela. O recorte que vem a seguir permite entender a natureza móvel do processo identitário, na medida em que o mesmo sujeito-leitor explicita a satisfação proporcionada pela leitura num outro lugar, desestabilizando, também, o conceito de lugar, tido como real e concreto, definido "como identitário, relacional e histórico" (AUGÉ, 1994, p.73).

A4 PED(3) - ... Para mim não tem nada mais gostoso que um sofá, ou cama, um capuccino e a companhia de um livro bem legal.

Com todas as contradições que a sociedade da informação e da comunicação impõe, parece-me pertinente pensar lugares e não-lugares como nômades, num deslocamento de linhas e atravessamentos que criam outros percursos e evocam 
palavras, num movimento de (re)composição, inclusive da subjetividade. Se lugar e não-lugar são polaridades fugidias, uma vez que o primeiro jamais é totalmente apagado e o segundo nunca se realiza completamente (AUGÉ, 1994, p.74), ambos se misturam nos dizeres do aluno-leitor em questão. Há, também, nas representações de A4_PED(3), a intromissão de uma outra voz, a do discurso propagandístico (... não tem nada mais gostoso que um sofá, ou cama, um capuccino e a companbia de um livro bem legal), o que pressupõe, ainda, um prolongamento do não-lugar (propaganda) para o lugar (sofá, ou cama), característica presente noutro recorte que segue:

A6_PED(2) - ... Já tentei ler na tela mas fica descômodo e logo perco a vontade, ler mesmo é sentada em sofá, confortável, em uma rede ou deitada na cama, além de relaxar, consigo esquecer os problemas e viajar na história. ...

Nessa perspectiva, penso a forma "(não-)lugar" como aquela que permite (des)identificações nos e pelos (des)dobramentos fugazes, num processo de (re)configuração do lugar no não-lugar, e vice-versa. No imaginário dos alunosleitores está presente a ideia de leitura como uma atividade que proporciona prazer e relaxamento, como, por exemplo, a leitura dos grandes romances, com longas descrições das ações e dos sentimentos de personagens fictícios, numa transposição da vida para outro plano, artístico e fantasioso. Essa tendência, bastante forte nos anos 80 , ainda se manifesta nos dias atuais, pois, ao ser questionado sobre a frequência ou as opções de leitura, o sujeito logo pensa em romances, o que acontece com A6_PED(2) e, em especial, com A4_PED(3), que associa a leituraliteratura (livro bem legal) a um lugar que é, também, prazeroso, confortável para ler.

Diferentemente do texto-tela, talvez o texto-papel proporcione ao sujeitoleitor mais comodidade espacial e maior conforto na atividade de uma leitura mais descomprometida; contudo, a (trans)mutação do corpo é inevitável, tanto na relação com o texto-papel quanto com o texto-tela. Ao iniciar a oração com o advérbio temporal (Já) - que pressupõe antecipação, precocidade -, o aluno-leitor não apenas expõe sua tentativa de ler na tela como também se serve da assertiva para encaminhar seus argumentos a respeito da leitura na tela em relação à leitura no papel. Essa antecipação manifestada pelo aluno-leitor vai ao encontro da abordagem sobre a sociedade do controle, feita por Deleuze (1990 [1992, p.224]): o "homem não é mais o homem confinado, mas o homem endividado", posto que "o controle é de curto prazo e de rotação rápida, mas também contínuo e ilimitado".

Diante da efemeridade, a busca constante é por saciar faltas e desejos: mesmo ao passear, em A4_PED(1), por exemplo, emerge a procura por algo busca indefinida, mas que representa algo legitimado pela sociedade: estar ali na 
tela e fazer parte do mundo das tecnologias de informação e comunicação. Tratase, ainda, de uma relação de poder-saber, que coloca o aluno-leitor numa posição privilegiada. Essa ideia de poder aparece marcada num recorte de outro aluno-leitor, que destaca, inclusive, a importância de se fazer uso do objeto tecnológico para alcançar um desejo de conhecer algo - domínio de saber engendrado pelas práticas sociais contemporâneas (Com o advento da Internet possibilitou maior acesso a tudo que se queira ler. Essa janela da tecnologia tem esse poder..., em A2_PED). Na busca pelo saber, o alunoleitor deseja a completude (acesso a tudo) que, no imaginário, é proporcionada pela internet (janela) - uma metáfora que corresponde tanto à abertura, às possibilidades, ao acesso aos caminhos que podem ser trilhados, quanto ao vazio do olhar.

Retomando o verbo passear, do recorte de A4_PED(1), o vazio também se revela, na medida em que "ir a algum lugar"12 implica ser levado ou transportado, (in) voluntariamente. A expressão "algum lugar", composta por um pronome indefinido, pode apontar incerteza e, ainda, busca pelo nada e pelo tudo ao mesmo tempo. Numa contradição, e mesmo ancorado na vontade de navegar e de realizar leituras na internet, o aluno-leitor faz despontar que, diante de várias páginas e muitas informações, acaba não vendo (ou lendo?) nada. A dispersão se difunde, carregando a fragmentação e as (in)certezas a respeito dos acontecimentos contemporâneos, que parecem ser verdadeiros e, ao mesmo tempo, vazios. Sobre esse aspecto, trago as considerações de Foucault (1979 [2004, p.5]): é preciso "considerar que existe todo um escalonamento de tipos de acontecimentos diferentes que não têm o mesmo alcance".

A característica do vazio, mais que uma ausência ou um vácuo, representa "um novo conteúdo" e, assim, o resultado é "o excesso como vazio e o vazio como liberdade de forjar novos e intensos conteúdos existenciais" (SILVA, 2005, p.xixiii). Esse excesso como vazio aparece materializado, por exemplo, em A4_PED(1): o uso de palavras no plural (Nestas páginas... assuntos nos sites variados); a escolha do adjetivo que expressa quantidade e variedade (variados); a sequência discursiva que indica a comparação entre dois sites ou mais (é uma forma de pesquisar fazendo paralelos). Falar em excesso e em vazio não significa desconsiderar a produção de sentidos do leitor, mas pensar nos efeitos dessas noções no que diz respeito à produção de subjetividades. Nessa perspectiva, o imbricamento entre querer e não-querer vivenciar o "novo" parece se constituir no vazio, mas carrega marcas do "já-lá", como no recorte que segue:

12. Cf. Houaiss. 
A4_PED(2) - ... Gosto muito de trocar mensagens por e-mail, uma forma rápida e eficiente, principalmente quando é preciso comprovar e documentar. Entre ler um texto on-line e um texto impresso, ainda prefiro as impressões, afinal os textos são escritos, revisados, editados e em geral tem um vocabulário muito mais rico. ...

O "já-dito" sobre o texto-papel circula no imaginário do sujeito-leitor que, sabendo da importância da leitura para a função de educador e do uso dos meios de comunicação nos dias atuais, expressa uma vontade de saber, de ser e fazer aquilo que os outros fazem, ou esperam que ele faça, na função que assume na sociedade (aluno-professor). Esse discurso se instala e funciona como legitimado, efeito do que é difundido principalmente no meio pedagógico: é preciso ler e usar as novas tecnologias. $\mathrm{O}$ advérbio temporal (ainda) sustenta a ideia da falta, de um possível atraso (no tempo), diante dos imperativos do mundo contemporâneo; o desejado pelos outros - colegas de profissão, coordenadores, diretores, alunos, pais de alunos, professora-pesquisadora, etc. - é que as leituras sejam feitas na tela, on-line, seguindo o discurso "da moda". Entretanto, o aluno-leitor, dada a história que o constitui, prefere a leitura dos textos impressos e, como justificativa, aponta certa resistência, fundada na ameaça que as "novas" tecnologias podem trazer para a qualidade de um texto.

Na sequência prefere ler textos impressos que textos on-line, há uma possível evidência de que qualquer que seja a informação disponibilizada e buscada nos sites (necessidade ou diversão), o aluno-leitor elege a versão impressa para a leitura. Na internet, o ato de fazer algo sem compromisso é mais atraente, tem um funcionamento que é da ordem do espetacular, o que pode justificar a opção do aluno pela leitura do texto-papel, quando se trata de uma pesquisa ou de uma leitura que exige mais concentração. Nessa comparação entre o texto-tela e o texto-papel, o alunoleitor expressa, também, seu imaginário sobre os textos impressos: características sobre a construção formal (revisados; editados; vocabulário muito mais rico) o colocam como diferente e mais confiável que o texto on-line, o que parece uma tentativa de, novamente, justificar que não lê textos on-line porque eles não são como os impressos.

O imaginário de que o texto-papel é bem escrito, é cuidadosamente revisado, vem das discursividades legitimadas pela sociedade e tomadas como verdade pelo aluno-leitor, que denuncia seu auto-controle como parte de uma ordem social de controle mais ampla: até suas justificativas que dizem respeito ao uso dos e-mails se pautam em procedimentos considerados concretos (comprovar edocumentar) e bastante comuns aos relacionados ao material impresso. Tanto a idealização do texto-papel quanto a possível (des)valorização do texto-tela podem ser entendidas, nesse caso, em relação aos jogos de poder-saber que constituem as relações sociais, de forma 
que as regras criadas, éticas e estéticas ao mesmo tempo funcionam como "modos de existência" (DELEUZE, 1996 [2005, p.76]). Assim, o processo de subjetivação caracteriza um acontecimento que, por sua vez, se configura nas injunções de poder, conforme emerge no excerto abaixo:

A1_BIO - ... Quando utilizo a internet converso com amigos, recebo e-mails, pesquiso sobre temas variados, mas na maioria das vezes temas que envolvam o conhecimento de Biologia. Eu prefiro ler textos impressos, compreendo melhor quando estão na folha, acho que a luz do computador irrita os meus olhos e me dá dor de cabeça. Gosto de ler livros eles tem muito mais informações do que os textos na internet. Em suma a leitura na internet é importante, mas não é o único meio pelo qual podemos nos informar.

O efeito de poder-saber se materializa no excerto em questão: por um lado, com a conjunção temporal (Quando), que introduz uma circunstância do uso da tecnologia, de modo a marcar que a prática não é uma constante; por outro lado, com a conjunção coordenada adversativa (mas), que expressa uma restrição e traz vinculada uma justificativa ancorada no discurso científico (... temas que envolvam o conbecimento de Biologia). A legitimação do texto impresso, em detrimento do on-line, está apoiada em proposições em torno do conteúdo (Gosto de ler livros eles tem muito mais informações do que os textos na internet) e do suporte (Eu prefiro ler textos impressos, compreendo melhor quando estão na folha), mas os argumentos do aluno parecem não se sustentar. Nesses dizeres, emergem os jogos de verdade sobre o texto-papel, os quais podem ser entendidos não como "a descoberta das coisas verdadeiras, mas as regras segundo as quais, a respeito de certas coisas, aquilo que um sujeito pode dizer decorre da questão do verdadeiro e do falso" (FOUCAULT, 1984 [2004, p.235]).

A partir dos jogos de verdade, o aluno-leitor torna-se portador de saberes com status científico, e sua postura, com relação à leitura, aponta para a transitoriedade nas relações do sujeito para com o objeto-máquina (. . . a leitura na internet é importante, mas não é o único meio pelo qual podemos nos informar). Assim, os efeitos de verdade determinam posições discursivas que podem e devem ser exercidas pelo sujeito, de forma a viabilizar relações sociais inscritas em determinada ordem do discurso: no caso em pauta, o discurso cristalizado (da ciência) e o discurso contemporâneo (da tecnologia). Nos relatos de alunos do curso de Ciências Biológicas, diferentemente dos demais (Matemática e Pedagogia), os dizeres estão quase sempre relacionados à questão do científico ${ }^{13}$, das pesquisas acadêmicas, como no recorte que segue:

A13 $\mathrm{BIO}$ - ... Utilizo a internet com frequência e acho que ajuda muito em certas situações, por exemplo pesquisas para trabalhos científicos, leio textos científicos 
pois faço um trabalho relacionado a câncer e preciso da internet. Leio tanto em revistas, livros quanto na internet e não vejo muita diferenças pois tem muitos textos que são de livros e estão na internet.

Tanto a objetivação quanto a subjetivação compreendem o pensar e o agir dentro de um conjunto de práticas que proporcionam o espaço para "novas" experiências e vivências no cenário da tecnologia, como coloca A1_BIO (... converso com amigos, recebo e-mails, pesquiso sobre temas variados). Contudo, muitas dessas práticas poderiam ser realizadas sem o acesso à internet, como atesta (e se contradiz, ao mesmo tempo) A13_BIO (... preciso da internet... não vejo muita diferenças pois tem muitos textos que são de livros e estão na internet), ou nos dois suportes, como permitem entrever outros recortes. Ainda que tentem se ancorar no estatuto de valor do vocábulo "científico" e declarem que buscas na internet são para fins específicos, voltados para o universo da Biologia, a visão de leitura de A1_BIO e A13_BIO é bastante utilitarista, embora não deixe de privilegiar interesses.

\section{PALAVRAS FINAIS...}

As imagens que os alunos fazem de si enquanto leitores e, também, do processo de leitura na tela funcionam como memória daquilo que já faz parte deles, que já os constitui. Nesse sentido, o "novo" parece ser produzido nas e pelas "novas" subjetividades perpassadas pelos dizeres dos alunos-leitores, dizeres esses que não correspondem a uma oposição leitura-texto-tela e leitura-texto-papel, mas ao "entre", ao atravessamento de um no outro, numa relação de dobramento e desdobramento dos discursos.

Esse "entre" aponta, ainda, para a heterogeneidade constitutiva do sujeito e da linguagem, de modo que a emergência de "novas" subjetividades faz vir à tona, também, processos identitários que se opõem e se completam simultaneamente, bem como revelam a alteridade do discurso. Pensar nos termos de heterogeneidade e alteridade é colocar em jogo "a unicidade de todo o dizer, apontando para a presença do outro no dizer daquele que aparenta 'um'" (CORACINI, 2003, p.251) e expondo a presença do outro na constituição de determinado discurso. É sob essa ótica da não univocidade que os recortes tomados para discussão se constituem.

13. Nas respostas da questão "Que tipos de textos on-line você lê? Por que?", do questionário do projeto-piloto da pesquisa, os textos apontados são os científicos (textos, artigos, pesquisas, novidades, etc.). 


\section{REFERÊNCIAS BIBLIOGRÁFICAS}

AMARANTE, M. de F. S. (2005) Discurso Pedagógico em um Contexto de Ensino/Aprendizagem de Inglês a Distância: Condições de Produção e Materialidade Lingüística. Letras: Revista da Faculdade de Letras. PUC-Campinas, SP: Centro de Linguagem e Comunicação. Volume 241, número 1, p.9-27.

- (2008) Transposição didática e leitura interpretativa no ciberespaço: uma nova ordem do discurso pedagógico?. (no prelo).

AUGÉ, M. (1994) Não-lugares: introdução a uma antropologia da supermodernidade. Trad. Maria L. Pereira. Campinas: Papirus.

BAUMAN, Z. (1999) Globalização: as consequências humanas. Trad. Marcos Penchel. Rio de Janeiro: Jorge Zahar.

BRUNO, F. (2006). Dispositivos de vigilância no ciberespaço: duplos digitais e identidades simuladas. Revista Fronteiras - Estudos Midiáticos, São Leopoldo/RS, v. VIII, p.152-159.

CORACINI, M. J. (2003) A escamoteação da heterogeneidade. In: CORACINI, M. J. \& BERTOLDO, E. S. (orgs.). O desejo da teoria e a contingência da prática: discursos sobre/na sala de aula (língua materna e língua estrangeira). Campinas: Mercado de Letras. p.251-268.

DERRIDA, J. (2001). Papel-máquina. Trad. Evandro Nascimento. São Paulo: Estação Liberdade, 2004.

DELEUZE, G. (1968) Diferença e repetição. Trad. Luiz Orlandi, Roberto Machado. 2 ed. Rio de Janeiro: Graal, 2006.

(1990) Conversações. Trad. Peter P. Pelbart. Rio de Janeiro: Ed. 34, 1992.

(1996) O mistério de Ariana. Trad. Edmundo Cordeiro. 2 ed. Lisboa: Veja Passagens, 2005.

FOUCAUlT, M. (1971) A ordem do discurso. Trad. Laura Fraga de Almeida Sampaio. 9 ed. São Paulo: Edições Loyola, 2003.

(1979) Microfísica do poder. 20 ed. Rio de Janeiro: Edições Graal, 2004.

(1984) A ética do cuidado de si como prática da liberdade. In: Ética, sexualidade, política. Ditos e escritos V. Trad. Elisa Monteiro e Inês A. D. Barbosa. Rio de Janeiro: Forense Universitária, 2004. p.264-287.

GREGOLIN, M. R. (2003) O acontecimento discursivo na mídia: metáfora de uma breve história do tempo. In: GREGOLIN, M. R. (org.). Discurso e mídia: a cultura do espetáculo. São Carlos: Claraluz. p.95-110.

HOUAISS, A.; VILLAR, M. S. (2001) Dicionário Houaiss da Lingua Portuguesa. Rio de Janeiro: Objetiva.

LEMOS, A. (2004) Cibercultura: tecnologia e vida social na cultura contemporânea. Porto Alegre, RS: Sulina.

LÉVY, P. (1996) O queéo virtual?. Trad. Paulo Neves. 3 ed. São Paulo: Ed. 34. . (2004) Uma perspectiva vitalista sobre a cibercultura. In: LEMOS, A. Cibercultura: tecnologia e vida social na cultura contemporânea. Porto Alegre, RS: Sulina, 2004. p.11-13.

MINISTÉRIO DA EDUCAÇÃO E CULTURA (MEC). Programa Nacional de Informática na Educação (PROINFO). Disponível em: < $\underline{\text { http://www.proinfo.mec.gov.br/ }>}$

PÊCHEUX, M. (1975). Semântica e discurso: uma crítica à afirmação do óbvio. Campinas: Ed. da UNICAMP, 1997.

ROMÃO, L. M. S.; BENDETTI, C. R. (2008) A navegação do sujeito no discurso jornalístico impresso e eletrônico. In: Verso \& Reverso, v. 49, p.1-12. 
SILVA, J. M. (2005) Apresentação - Vazio e comunicação na era "pós-tudo". In: LIPOVETSKY, G. A era do vazio: ensaios sobre o individualismo contemporâneo. Trad. Therezinha Monteiro Deutsch. Barueri, SP: Manole. p.ix-xiv.

SOARES, D. (1997) A globalização numa perspectiva sociocibernética. In: Revista Contracampo - n.1. Disponível em: < http://www.compuland.com.br/delfim/cc2.htm>. Acesso em 03 abr. 2007.

TRIVINHO, E. R. (2004) Comunicação, glocal e cibercultura: bunkerização da existência no imaginário mediático contemporâneo. In: XIII Encontro Nacional da COMPÓS. Disponível em: $<$ http://www.comunica.unisinos.br/tics/textos/2004/2004_et.pdf $>$. Acesso em 21 jul.2008.

WERTHEIM, M. Uma bistória do espaço: de Dante à internet. Rio de Janeiro: Jorge Zahar, 2001.

Recebido: 30/08/2010

Aceito: 24/01/2012 